\title{
Kampf der Bilder
}

\author{
Ein Vorwort
}

Dass die medial verbreitete Botschaft und insbesondere das medial verbreitete Bild unseren Zugriff auf die Welt verändert haben, kann man vielleicht am augenfälligsten in den großen Metropolen erfahren, ja, man kann es dort geradezu körperlich erleben: Berlin, Istanbul, London, Los Angeles, Peking oder Mexico City sind Städte ohne öffentliche Räume - so sie denn überhaupt Städte im hergebrachten Sinne sind und nicht viel mehr architektonische, wirtschaftliche, politische, soziale und kulturelle Konglomerate, die nicht von ungefähr an die Rhizome des Internets erinnern -; Städte ohne öffentliche Räume jedenfalls in der tradierten, eurozentrischen Bedeutung des Begriffs, der den Marktplatz, die Agora als einen Treffpunkt, als einen Versammlungsund Diskussionsort bezeichnet, der für die politische Willensbildung - wie auch immer sie sich in den Jahrhunderten europäischer Geschichte dargestellt haben mag - von entscheidender Bedeutung gewesen ist. Und auch wenn Protestbewegungen wie Occupy Wallstreet, wenn Manifestationen von Protest und Widerstand die urbanen Räume wie etwa den Maidan-Platz in Kiew, den Tahrir-Platz in Kairo oder den Gezi-Park in Istanbul in ihren öffentlichen Funktionen - wenn auch nur vorübergehend - zurückerobern können, oder wenn künstlerische Interventionen mit ästhetischen Mitteln versuchen, aus dem durch ein vollständig ökonomisiertes Stadtbild eilenden Passanten einen reflektierend innehaltenden Betrachter zu machen, so hat sich die globale Realität der Metropolen dennoch grundlegend gewandelt: Längst ist der virtuelle Raum zum eigentlichen öffentlichen Raum geworden. Allerdings besteht er unter solcherart veränderten Bedingungen in seinen wirtschaftlichen, politischen, sozialen und kulturellen Funktionen nach wie vor, ja, er ist erweitert und entgrenzt, größer, pulsierender und einflussreicher als jemals zuvor in der Geschichte der Menschheit. Es besteht also kaum ein Grund für ein kulturkritisches Bedauern über den Verlust des öffentlichen Raums alter Observanz, aber gleichwohl die deutliche Erfordernis, über diese Umwälzung professionell nachzudenken, die Möglichkeiten und nicht zuletzt die Risiken zu bedenken, die Widersprüche zu registrieren, die wesentliche Bestandteile dieses Systemwandels sind. 
War der öffentliche Raum jener Zeitalter vor der Etablierung des Internets mit Bildern ausgestattet, die über die Verfasstheit von Staat und Gesellschaft, aber auch über Protest, Opposition und Rebellion Auskunft gaben - Darstellungen an Schlössern, Rathäusern und Parlamenten, Schandbilder, Flugblätter und Karikaturen und vieles, vieles mehr -, so ist auch der virtuelle Raum bis zum Bersten mit Bildern angefüllt, wie beispielsweise der Blick in eine Installation des niederländischen Künstlers und Kreativdirektors Erik Kessels zeigt, der 2013 in einer Ausstellungshalle in San Francisco sämtliche Fotos ausgedruckt aufgeschüttet hat, die an nur einem einzigen Tag auf nur einer einzigen Website (flickr) gepostet wurden (Abb. 1). Und viele dieser Bilder sind politischer Natur, auch solche, die ganz ohne politische Inhalte auszukommen scheinen: Neue Ikonografien des politischen Bildes sind im und durch das Internet entstanden, affirmative und subversive Bilder werden aufgenommen, inszeniert, manipuliert, werden verbreitet und verhalten sich auf kaum kontrollierte Weise viral, wie es eine aktuelle Metapher will, die nicht zufällig aus dem semantischen Feld der Epidemiologie entnommen ist; ein neuer Bilderglaube herrscht, auch eine neue Bilderskepsis. Und dies gerade in einer Epoche, die als spostfaktisches< Zeitalter ausgerufen wird, womit nicht etwa das Ende der faktischen Auswirkungen medial vermittelter Propaganda gemeint ist, sondern die fatale Tatsache, dass Affekt und Kalkül im politischen Handeln wirkmächtiger als je zuvor und unabhängig von aller demokratischen Kontrolle sich zunehmend gegen das aufklärerische Ideal tatsächlicher Wahrheit durchzusetzen drohen. Das Bild, das ein banales ebenso wie ein bedeutendes Ereignis im Augenblick seines Vollzugs in der ganzen Welt sichtbar machen kann, ist zudem eine Waffe von ungeheurer Schlagkraft geworden, und das nicht nur im metaphorischen Sinne des Wortes.

Kurz und gut: Es wird Zeit, dass gerade wir Kunsthistoriker uns mit dem Phänomen des politischen Bildes in Zeiten seiner globalen Allverfügbarkeit noch intensiver beschäftigen. Und wo könnte dies besser geschehen als im Haus der ehemaligen Kulturwissenschaftlichen Bibliothek Warburg, deren Gründer gerade die politische Botschaft von Bildern aller Medien in den Kanon kunstwissenschaftlicher Themen geholt hat und darüber hinaus die Distributionspotentiale der Kunstwerke und visuell wirksamen Phänomene im Blick hatte, der - wie er sie nannte - »automobilen Bilderfahrzeuge«, denen sich das Hamburger Warburg-Haus seit 2014 im Forschungsverbund Bilderfahrzeuge. Aby Warburg's Legacy and the Future of Iconology gemeinsam mit dem Warburg Institute (London), dem Deutschen Forum für Kunstgeschichte (Paris), der Humboldt-Universität (Berlin) und dem Kunsthistorischen Institut (Florenz) widmet.

Die Idee zum vorliegenden Band geht auf eine Tagung zurück, die unter dem gleichlautenden Titel Nähe auf Distanz. Eigendynamik und mobilisierende Kraft politischer Bilder im Internet am 14. Juni 2015 im Warburg-Haus stattfand, dessen Schwerpunktthema in den Jahren 2015-2016 die 'Kunst im Konflikt< behandelte. Ich danke Isabelle Busch und Judith Waldmann, auf deren Initiative hin die Tagung durchgeführt wurde, ich danke ihnen für die interes- 


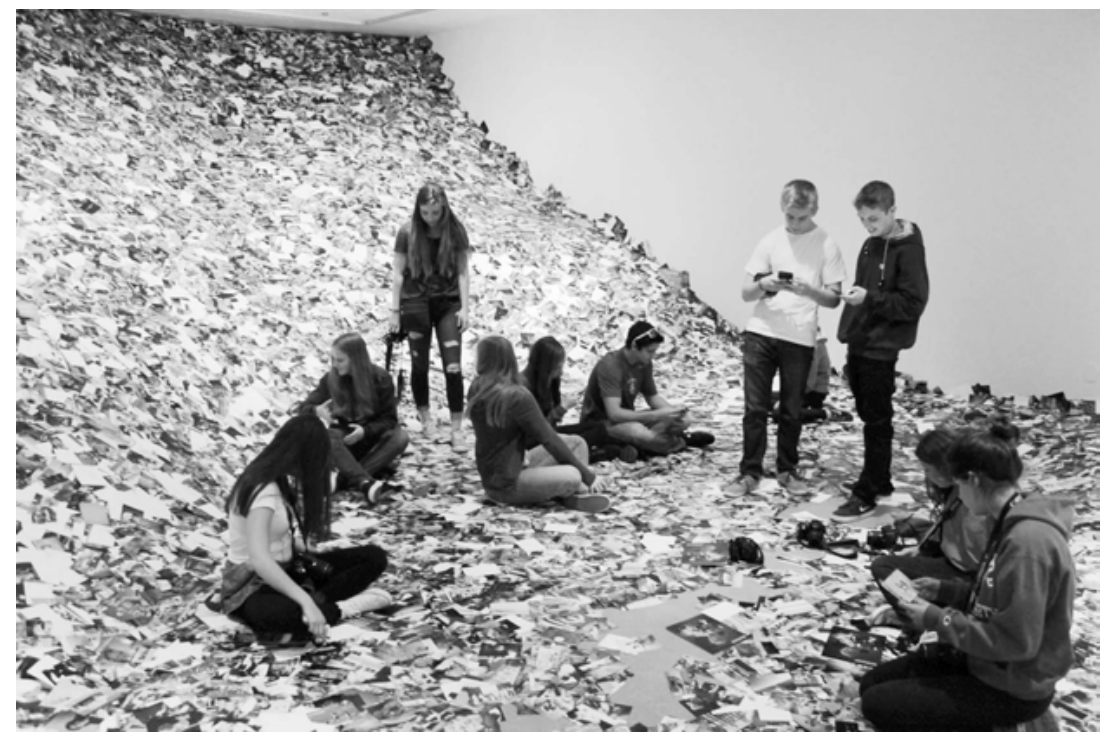

1. Erik Kessels:24 HRS in Photos, Installationsansicht, 2013, Pier 24, San Francisco

santen Konzeptgespräche zu diesem Buch sowie für die intellektuelle wie konzeptionelle Hartnäckigkeit, mit der sie das Gesamtprojekt vorangetrieben haben, dessen Ergebnisse sich nun weit über die ursprüngliche Veranstaltung hinaus entwickeln konnten. Dass die Tagung erfolgreich stattfinden, dass unser Buch erscheinen konnte, verdanken wir einer ganzen Reihe großzügiger Förderer: der Hamburger ZEIT-Stiftung Ebelin und Gerd Bucerius, der Hamburger Liebelt-Stiftung, dem Institut für Auslandsbeziehungen (ifa), Stuttgart, dem Verein der Freunde und Förderer des Kunstgeschichtlichen Seminars sowie der Aby-Warburg-Stiftung.

Die intensiven Diskussionen der letzten Jahre haben nun in einer Publikation ihren Niederschlag gefunden, die tiefe Einsichten in ein Thema bereithält, das über die akademische Auseinandersetzung mit dem Phänomen des Bildes im Internet hinaus gerade auch von höchster politischer und nicht zuletzt künstlerischer Aktualität ist. Kunstgeschichte als bereits in sich selbst interdisziplinäre geistes- und kulturwissenschaftliche Disziplin muss die professionelle Verantwortung dafür übernehmen, bildliche Phänomene sozialer, politischer, kultureller oder wirtschaftlicher Auseinandersetzungen verstehbar zu machen: Das Bild als Medium und als Waffe im politischen Konflikt ist auf wissenschaftlich geschulte Interpreten angewiesen, um uns den Bilderfluten, den visuellen Attacken nicht sprach- und handlungslos auszuliefern. Der vorliegende Band, so fragmentarisch das gesamte Themengebiet in ihm naturgemäß auch nur behandelt werden konnte, möchte seinen Beitrag zu einer Debatte liefern, deren globale Brisanz uns mit jedem Blick auf die Welt, mit jedem Blick in die Medien deutlich vor Augen tritt. 
